\title{
miR-1296-5p decreases ERBB2 expression to inhibit the cell proliferation in ERBB2-positive breast cancer
}

Gang Chen ${ }^{1,2+}$, Mingfeng He ${ }^{3 \dagger}$, Yin Yinn ${ }^{4 \dagger}$, Ting Yan ${ }^{5}$, Wenfang Cheng ${ }^{6}$, Zebo Huang ${ }^{2}$, Lan Zhang ${ }^{2}$, Huo Zhang ${ }^{2}$, Ping Liu ${ }^{2^{*}}$, Wei Zhu ${ }^{2^{*}}$ and Yichao Zhu H, $^{*}$

\begin{abstract}
Background: The tumor suppressive role of miR-1296 is observed in triple negative breast cancer (TNBC). However, the effect of miR-1296-5p in ERBB2-positive breast cancers remains obscure.

Methods: Whether ERBB2 was the target gene of the miR-1296-5p was predicted by online software, and determined by dual-luciferase activity assay. miR-1296-5p expression levels were determined in breast cancer samples (114 breast cancer tissues and 30 adjacent normal tissues) by using qRT-PCR. The effect of miR-1296-5p and inhibition of ERBB2/mTORC1 signaling on the downstream target was assessed by Western blot. SK-BR-3 and BT-474 breast cancer cell line was transfected with miR-1296-5p mimic after which cell proliferation and apoptosis were determined by the clonogenic assay and the flow cytometry system, respectively. In addition, the chemotherapeutic drug sensitivity of SK-BR-3 and BT-474 cells transfected with miR-1296-5p mimic were determined by MTT assay.

Results: The luciferase assay carrying ERBB2 3'-untranslated region-based reporters expressed in SK-BR-3 and BT-474 cells suggested that ERBB2 was the target gene of miR-1296-5p. MiR-1296-5p was significantly decreased in breast cancer tissues compared to adjacent normal tissues. Moreover, it was declined in ERBB2-positive breast cancer samples compared with that in ERBB2-negative breast cancer tissues. Overexpressed miR-1296-5p reduced its target protein level and mTORC1/S6 activation, inhibited the proliferation of ERBB2-positive breast cancer cells and sensitized these cells to cisplatin and 5-fluorouracil-induced apoptosis.
\end{abstract}

Conclusions: Our findings suggest that miR-1296-5p is involved in the regulation of proliferation in breast cancer cells via targeting ERBB2/mTORC1 signaling pathway.

Keywords: miR-1296-5p, ERBB2, Breast cancer, Proliferation, mTORC1

\section{Background}

ERBB2 (or HER2) is a receptor tyrosine kinase, of which the amplification occurs in approximate a quarter of breast carcinomas and is identifies as particularly aggressive tumors [1-3]. Over-expressed ERBB2 couples to two

\footnotetext{
*Correspondence: belliwether@163.com; zhuwei@njmu.edu.cn; zhuyichao@njmu.edu.cn

${ }^{\dagger}$ Gang Chen, Mingfeng He and Yin Yin contributed equally to this work

${ }^{2}$ Department of Oncology, First Affiliated Hospital of Nanjing Medical University, Nanjing 210029, People's Republic of China

${ }^{7}$ Department of Physiology, Nanjing Medical University, Nanjing 211166 People's Republic of China

Full list of author information is available at the end of the article
}

major oncogenic pathways (RAS-ERK and PI3K-AKT) that promote cell survival, proliferation, migration and invasion $[4,5]$. Although ERBB2-targetd therapy (herceptin or trastuzumab) has been successfully used to treat ERBB2-overexpressing tumors, patients' drug resistance curbs its clinical widespread use [6-8]. There is an imperious need to develop new and efficient targets for therapeutic intervention of ERBB2-positive breast cancers.

MicroRNAs (miRNAs) have a wide range of ability to regulate cell survival, proliferation, differentiation, migration, invasion and metastasis of breast cancers [9-11]. MiR-1296 is shown to down-regulate the synthesis phase of the cell cycle in prostate cancers [12]. MiR-1296 also 
induces cell apoptosis via PIM1-STAT3 signaling pathway in cervical cancer [13]. MiR-1296 is association with chemotherapeutic resistance and self-renewal capability in breast cancers [14]. In TNBC cells and tissues, miR1296 expression is significantly suppressed, and which sensitized TNBC cells to cisplatin treatment [15]. However, it is still largely unknown how specific miRNA functions affect ERBB2-positive breast cancers. Here, we demonstrated that miR-1296-5p decreases the expression level of ERBB2 to inhibit the cell proliferation in ERBB2positive breast cancer.

\section{Methods}

\section{Clinical samples}

A total of 114 breast cancer patients recruited from the First Affiliated Hospital of Nanjing Medical University from 2013 to 2016 were included in this study. Samples consisted of 114 of breast cancer tissues and 30 of adjacent normal tissues. All tissues were histopathologically confirmed by a pathologist who selected tumor areas with higher tumor cell density that was suitable for RNA isolation and immunohistochemistry (IHC). All the samples were pathologically examined and stored in liquid nitrogen for miRNA analysis. Ethical approval for the study was granted by the Clinical Research Ethics Committee, Nanjing Medical University. Written informed consent was taken from each participant.

\section{Cell culture}

SK-BR-3 human breast cancer cell line was purchased from the Cell Bank of Shanghai (Shanghai, China). BT-474 breast cancer cell line was kindly gifted from Dr. Tiansong Xia (First Affiliated Hospital of Nanjing Medical University). Cells were cultured in RPMI 1640 or DMEM medium, supplemented with $10 \%$ fetal bovine serum (Hyclone, Logan, UT, USA), at $37{ }^{\circ} \mathrm{C}$ in a humidified atmosphere with $5 \% \mathrm{CO}_{2}$.

\section{Dual-luciferase activity assay}

The 3'-UTR of human ERBB2 containing the putative target site for the miR-1296-5p was chemically synthesized and inserted at the $\mathrm{Xba \textrm {I }}$ site, immediately downstream of the luciferase gene in the pGL3-control vector (Promega, Madison, WI) by Integrated Biotech Solutions Co., Ltd (Shanghai, China), respectively. Twenty-four hours before transfection, cells were plated into 24-well plates $\left(1.5 \times 10^{5}\right.$ cells/well). PGL3-ERBB2-3'-UTR (200 ng) and pRL-TK (80 ng, Promega) were transfected in combination with 60 pmol miR-1296-5p mimic or miRNA mimic control using Lipofectamine 2000 (invitrogen). Luciferase activity was measured $24 \mathrm{~h}$ after transfection using the dual luciferase reporter assay system (Promega). Firefly luciferase activity was normalized to renilla luciferase activity for each transfected well. Three independent experiments were performed in triplicate.

\section{Western blot analysis}

SK-BR-3 or BT-474 cells were plated in 6-well plates $\left(6 \times 10^{5}\right.$ cells/well). Seventy-two hours after the transfection of miR-1296-5p mimic or miRNA mimic control, cells were harvested and homogenized with lysis buffer. Total protein was separated by $10 \%$ denaturing SDSpolyacrylamide gel electrophoresis. Western blot analysis was performed as described [16]. The primary antibodies for ERBB2, S6, Phospho-S6, beta-actin, and GAPDH were purchased from cell signaling technology (Danvers, MA). The expression levels of indicated proteins were normalized to GAPDH or beta-actin.

\section{Quantitative real-time PCR analysis for miRNA}

Breast cancer tissues and cells were isolated with Trizol reagent (Invitrogen, Carlsbad, CA). MiRNA fraction was purified using a mirVana ${ }^{\mathrm{TM}}$ miRNA isolation kit (Ambion, Austin, TX). The concentration and purity of the RNA samples were determined spectroscopically. The SYBR and U6 gene were used for detecting the gene amplification and normalizing the each sample, respectively. The primers of reverse transcription and polymerase chain reaction were purchased from RiboBio Co., Ltd (Guangzhou, China). QRT-PCR was performed according to the protocol of primer sets. PCR product amplification was detected by the level of fluorescence emitted by SYBR Green $\left(\mathrm{SYBR}^{\circledR}\right.$ Premix Ex Taq ${ }^{\mathrm{TM}}$ II, TaKaRa) which intercalated into double stranded DNA [17]. The $\Delta \mathrm{Ct}$ method was used for miRNA expression analysis of biopsy specimens. The cycle number at the threshold level of fluorescence $(\mathrm{Ct})$ for each sample was determined, and then calculating the $\Delta \mathrm{Ct}$ value. The $\Delta \mathrm{Ct}$ value was the subtraction between the $\mathrm{Ct}$ value of miR-1296-5p and the $\mathrm{Ct}$ value of U6: $\Delta \mathrm{Ct}=\mathrm{Ct}(\mathrm{miR}-1296-5 \mathrm{p})-\mathrm{Ct}$ (U6). The fold-change for miRNA compared to each controls was calculated using the $2^{-\Delta \Delta C t}$ method. PCR was performed in triplicate.

\section{Clonogenic assay}

SK-BR-3 or BT-474 cells were transfected with miR1296-5p mimic or miRNA mimic control and plated into 6-well plates at a density of 1000 cells/well, incubated at routine culture condition for 2 weeks, fixed and stained with crystal violet. The number of colonies were counted under a microscope from three independent replicates.

\section{Apoptosis assay}

SK-BR-3 cells were plated into 6 -well plates $\left(6 \times 10^{5}\right.$ cells/ well). Forty-eight hours after the transfection of miR1296-5p mimic or miRNA mimic control, flow cytometry 
was used to detect apoptosis of the transfected SK-BR-3 cells by determining the relative amount of annexin V-FITC-positive and propidium iodide (PI)-negative cells. Annexin V-FITC and PI were purchased from BD biosciences (San Jose, CA).

\section{RhoA and Rac1 activation assay}

For RhoA and Rac1 activation assays, breast cancer cells were plated into $35 \mathrm{~mm}$ dishes and transfected with miR-1296-5p mimic or miRNA mimic control. The experiments were then performed according to the manufacturer's protocol (Cytoskeleton Inc., Denver, CO, USA).

\section{In vitro drug sensitivity assay}

SK-BR-3 or BT-474 human breast cancer cells were plated into $35 \mathrm{~mm}$ dishes $\left(6 \times 10^{5}\right.$ cells/dish $), 100 \mathrm{nmol} / \mathrm{L}$ of the miR-1296-5p mimic or $100 \mathrm{nmol} / \mathrm{L}$ miRNA mimic control were transfected in SK-BR-3 cells, using lipofectamine 2000 (Invitrogen, Long Island, NY, USA). The miR-1296-5p mimic, miRNA mimic control were chemically synthesized by Shanghai GenePharma Company (Shanghai, China). Twenty-four hours after transfection cells were seeded into 96 -well plates $\left(5 \times 10^{3}\right.$ cells/well). Forty-eight hours after the drug treatment, cell viability was assessed by 3-(4,5-dimethylthiazol-2-yl)-2,5-diphenyl-tetrazolium bromide (MTT, Beyotime Biotechnology, Nantong, China) assay. The absorbance at $490 \mathrm{~nm}$ of each well was read on a spectrophotometer. The concentration at which drugs produced $50 \%$ inhibition of growth (IC50) was estimated by the relative survival curve. Three independent experiments were performed in quadruplicate.

\section{Statistical analysis}

Each experiment was repeated at least 3 times. Numerical data were presented as mean $\pm \mathrm{SD}$. The difference between means was analyzed with Student's t test. All statistical analyses were performed using SPSS 13.0 software (Chicago, IL). Differences were considered significant when $p<0.05$.

\section{Results}

\section{ERBB2 as the target genes of miR-1296-5p}

TargetScanHuman (http://www.targetscan.org) suspects that $E R B B 2$ is a target gene of the miR-1296-5p (Fig. 1a). To determine whether ERBB2 is the target gene of miR-1296-5p, the luciferase reporter vectors carrying the putative ERBB2 $3^{\prime}$-UTR target site for the miR1296-5p (pGL3-ERBB2-3'-UTR) were constructed and then transfected into SK-BR-3 or BT-474 cells. The relative luciferase activity was significant decreased in miR1296-5p-overexpressing cells than that in control cells
(Fig. 1b, c). Next, the miR-1296-5p mimics were transfected into SK-BR-3 or BT-474 cells and the expression levels of ERBB2 were examined by Western blot. We found that the expression of ERBB2 in miR-1296-5ptransfected cells was extremely depressed than that in control cells (Fig. 1d, e). Taken together, these results indicate that $E R B B 2$ is a target gene of the miR-1296-5p.

\section{MiR-1296-5 $p$ was down-regulated in breast cancer tissues and ERBB2-positive tissues}

To determine whether miR-1296-5p expression was associated with breast cancer, miR-1296-5p expressions in breast cancer tissues including 114 breast cancer tissues and 30 non-tumor adjacent normal tissues were examined. The expression level of miR-1296-5p was significantly declined in breast cancer samples compared with the non-tumor adjacent normal tissues (Fig. 2). Meanwhile, miR-1296-5p was significantly down-regulated in human ERBB2-positive breast cancer tissues compared with ERBB2-negative breast cancer tissues (Fig. 3).

\section{MiR-1296-5p suppressed mTORC1 signaling in breast cancer cells}

Previous studies reported that ERBB2 induction of the invasion and migration of breast cancer cells required activation of the small GTPases and mTOR signaling $[18,19]$. We examined the activation of RhoA, Rac1 and mTORC1 signaling in miR-1296-5p-transfected cells and the control cells. We found that the activation of RhoA and Rac1 were not significantly changed in miR-1296-5ptransfected cells compared to those in control cells (Fig. 4a, b). Interestingly, the phosphorylation of S6, the direct downstream of mTORC1 signaling, was obviously down-regulated in miR-1296-5p-transfected SK-BR-3 or BT-474 cells (Fig. 4c, d). These results indicate that miR1296-5p mediates the mTORC1 signaling, but not Rho signaling, in breast cancer cell lines.

\section{MiR-1296-5p inhibited cell proliferation of breast cancer cells}

Clonogenic assay revealed that SK-BR-3 or BT-474 cells transfected with miR-1296-5p were shown significantly reduced clone formation compared with the control cells (Fig. 5a, c). Moreover, the overexpression of miR-1296-5p did not alter the apoptosis of SK-BR-3 cells (Fig. 5b). These results demonstrate that miR-1296-5p inhibits cell proliferation of breast cancer cell line.

MiR-1296-5p turned SK-BR-3 cells more vulnerable to the apoptosis induced by cisplatin and 5 -fluorouracil

Since the miR-1296-5p inhibits cell proliferation of breast cancer cell line, a hypothesis is proposed that 


\section{a $\begin{array}{lll}\text { ERBB2 } 3 \text { '-UTR } & \text { 5'...CCUGAGAGGGGAAGC......GGCCCUAA... } \\ \text { hsa-miR-1296-5p } & 3{ }^{\prime} \quad \text { CCUCUACCUCGGUCCCGGGAUU }\end{array}$}

b

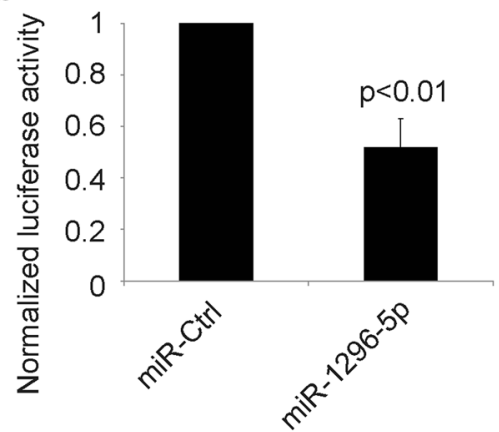

d

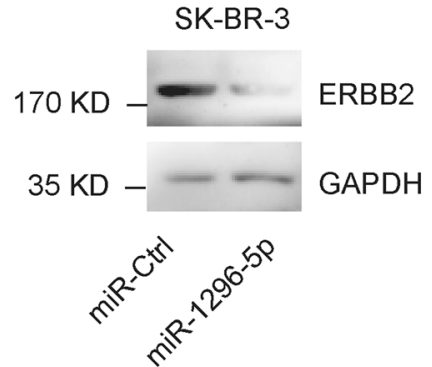

C

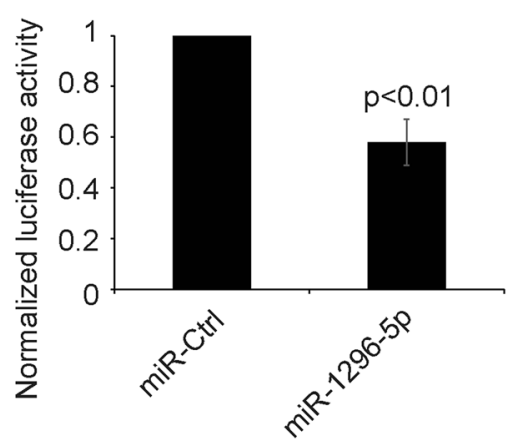

e

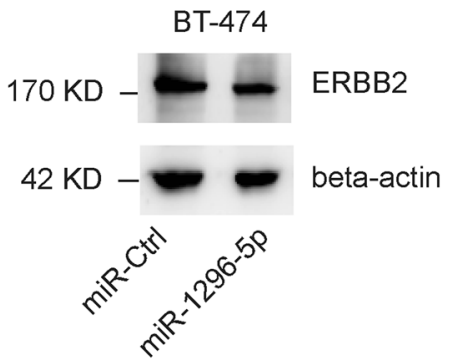

Fig. 1 ERBB2 as target of miR-1296-5p. a The seed sequence of miR-1296-5p is complementary to the 3'-UTR of ERBB2. b, c Luciferase assay showing reduction in reporter activity (relative luciferase units) after co-transfection of ERBB2-3'UTR with miR-1296-5p in SK-BR-3 or BT-474 cells. d, e Western blot analysis showing suppression of ERBB2 protein levels in SK-BR-3 or BT-474 cells after miR-1296-5p overexpression

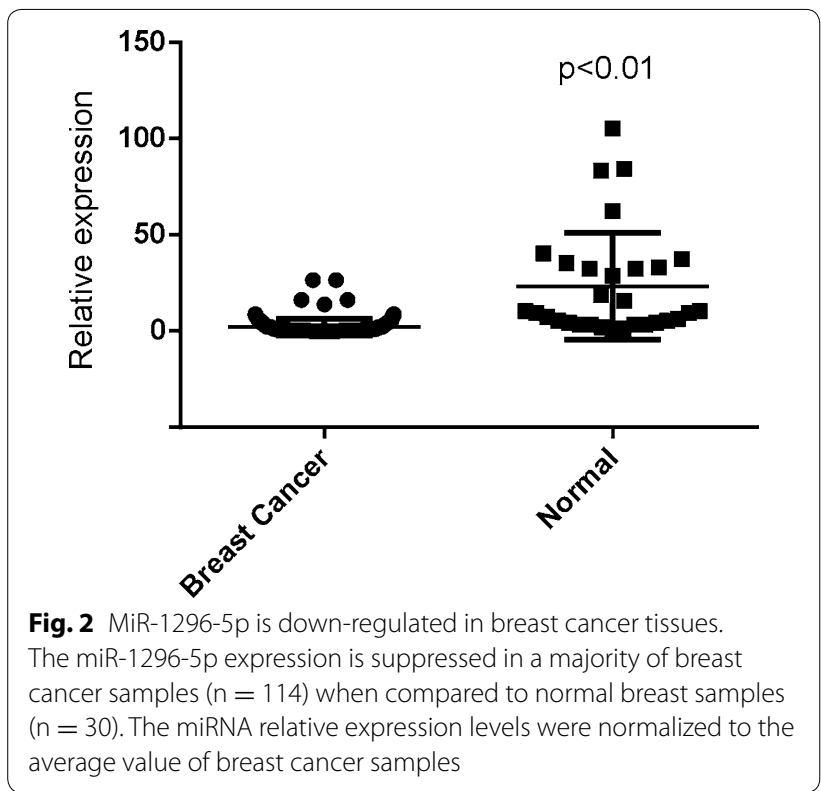

miR-1296-5p might evoke the apoptosis of ERBB2-positive breast cancer cells by weakening drug resistance. Thus, drug-induced apoptosis in chemotherapy was evaluated through transfecting SK-BR-3 or BT-474 cells with miR-1296-5p. According to MTT assay, cells transfected with miR-1296-5p mimic exhibited greatly decreased resistance to cisplatin and 5-fluorouracil (5-FU) compared with the control cells (Fig. 6a, b). However, miR1296-5p did not turn the vulnerable to the apoptosis induced Gemcitabine and HCPT, respectively (Fig. 6a). These results demonstrate that miR-1296-5p turns breast cancer cells more vulnerable to the apoptosis induced by cisplatin and 5-FU.

\section{Discussion}

In this study, we find that miR-1296-5p expression is suppressed in a majority of breast cancer samples when compared to normal breast samples. Previous study has showed that the expression level of miR-1296 is 


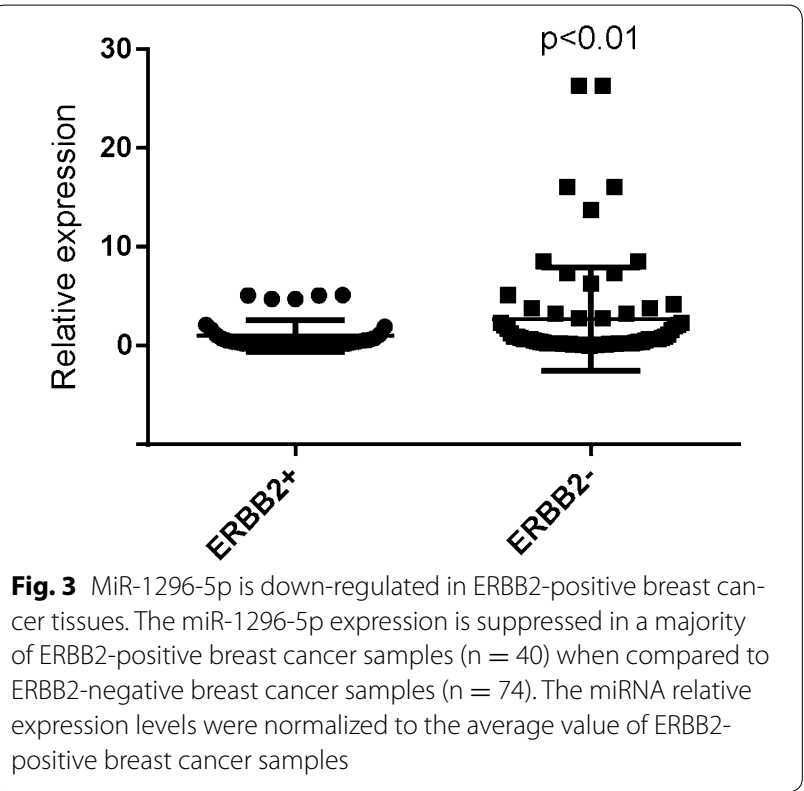

decreased in prostate cancer and triple negative breast cancer (TNBC) samples [12, 15], suggesting that it is a tumor-suppressor gene in these cancers. MiRNA-next generation sequencing (NGS) analysis reveals miR-1296 is associated with chemotherapeutic resistance and self-renewal capability in breast cancers [14]. MiRNA microarray analyses demonstrate that miR-1296 affects PIM1-STAT3 pathway and subsequently induces cell apoptosis in cervical cancer [13]. These studies show that the function of miR-1296 as a tumor-suppressor might be more conflicting. In the other diseases, miR1296 is putative negative regulators of XAF1 in lymphoblastoid cell lines (LCLs) during long-term cell culture, suggesting that miR-1296 is participated in the terminal immortalization of LCLs [20]. The expression of miR1296 is increased in sera of chronic congestive heart failure (CHF) patients, which may be a potential prognostic marker in CHF [21]. Here, we found that miR-1296-5p was decreased in ERBB2-positive breast cancer samples when compared to ERBB2-negative breast cancer samples, suggesting that miR-1296-5p might be a tumor-suppressor gene in ERBB2-positive breast cancer.

It has been reported that miR-1296 overexpression significantly inhibit the expression of cyclin D1 and cell proliferation of TNBC cell lines [15]. In human prostate carcinoma PC3 cells, knockdown of miR1296 increases both minichromosome maintenance 2 (MCM2) mRNA and protein [12]. To the contrary, miR-1296 overexpression decreases the expression of

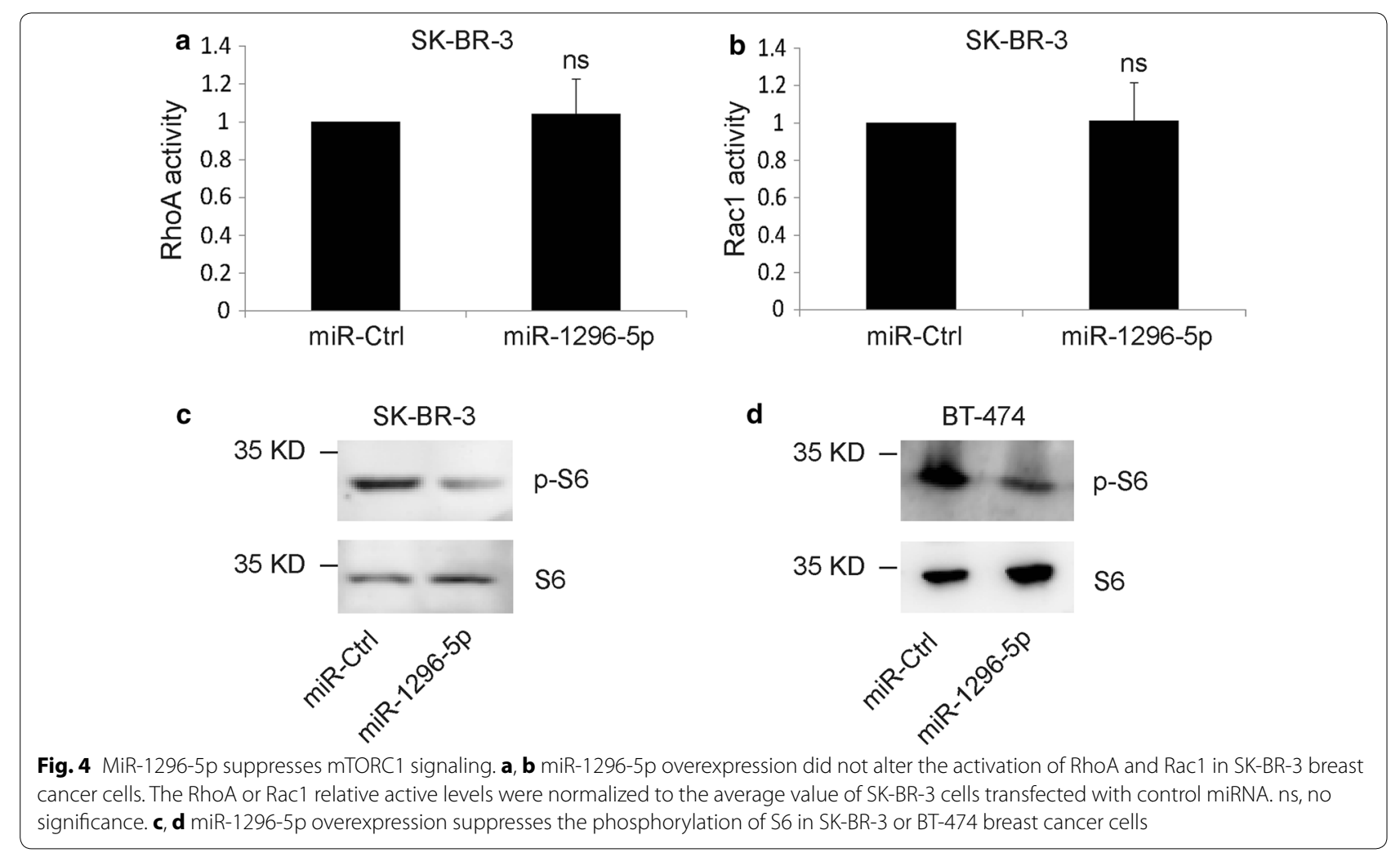


a

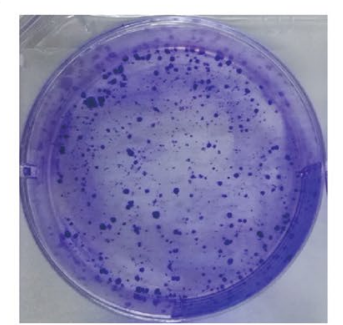

b

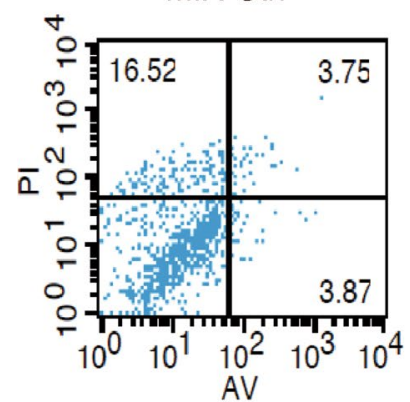

C

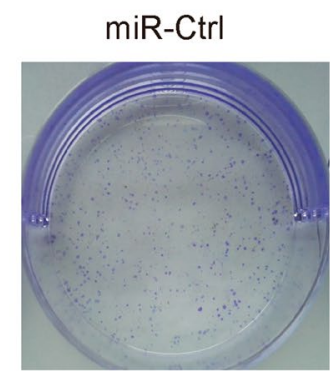

miR-1296-5p

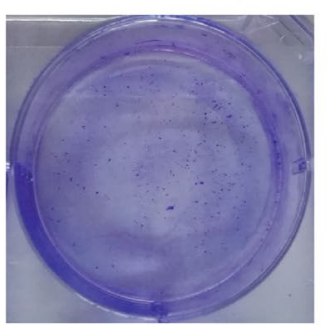

miR-1296-5p

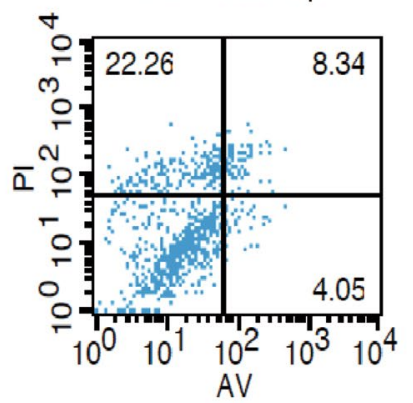

miR-1296-5p

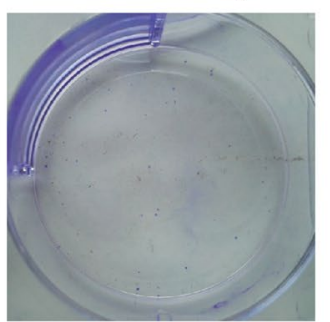

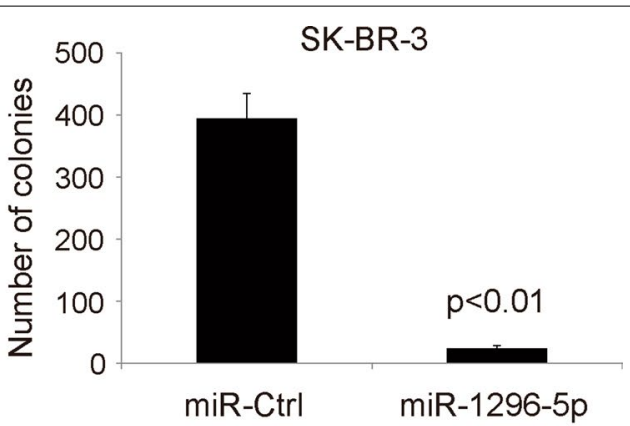

SK-BR-3
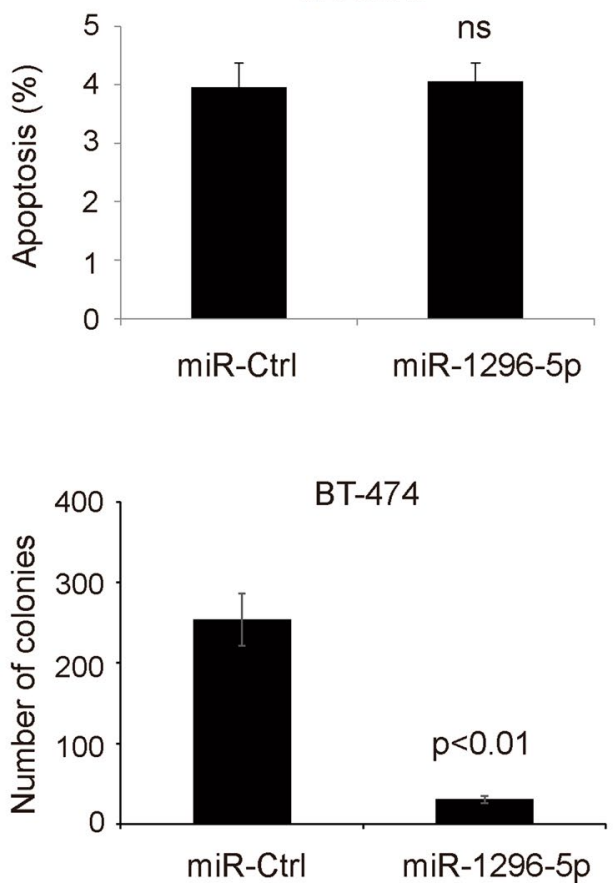

Fig. 5 MiR-1296-5p suppresses the colony formation ability of ERBB2-positive breast cancer cells. a, c miR-1296-5p overexpression reduced the colony formation ability of SK-BR-3 or BT-474 breast cancer cells when compared to control miRNA-expressing cells. b miR-1296-5p overexpression did not alter the apoptosis of SK-BR-3 breast cancer cells when compared to control miRNA-expressing cells. ns no significance

MCM2 mRNA and protein, and shortens the synthesis phase of the cell cycle [12]. Here, we found that miR1296-5p inhibits the proliferation of ERBB2-positive breast cancer cells by decreasing ERBB2 expression. ERBB2 can activate mTORC1/p70S6K signaling in human breast cell lines and breast cancers [22]. Consistent with the report, we found that miR-1296-5p suppressed ERBB2 expression and mTORC1 signaling, subsequently inhibited the proliferation of ERBB2-positive breast cancer cells.

MiR-1296 expression sensitized TNBC cells to cisplatin treatment [15]. We also found that miR-1296-5p sensitized SK-BR-3 cells to cisplatin and 5-FU-induced apoptosis. Therefore, it is possible that miR-1296-5p may modulate the resistance of chemotherapeutic agents, and serve as novel targets for antitumor therapies. 

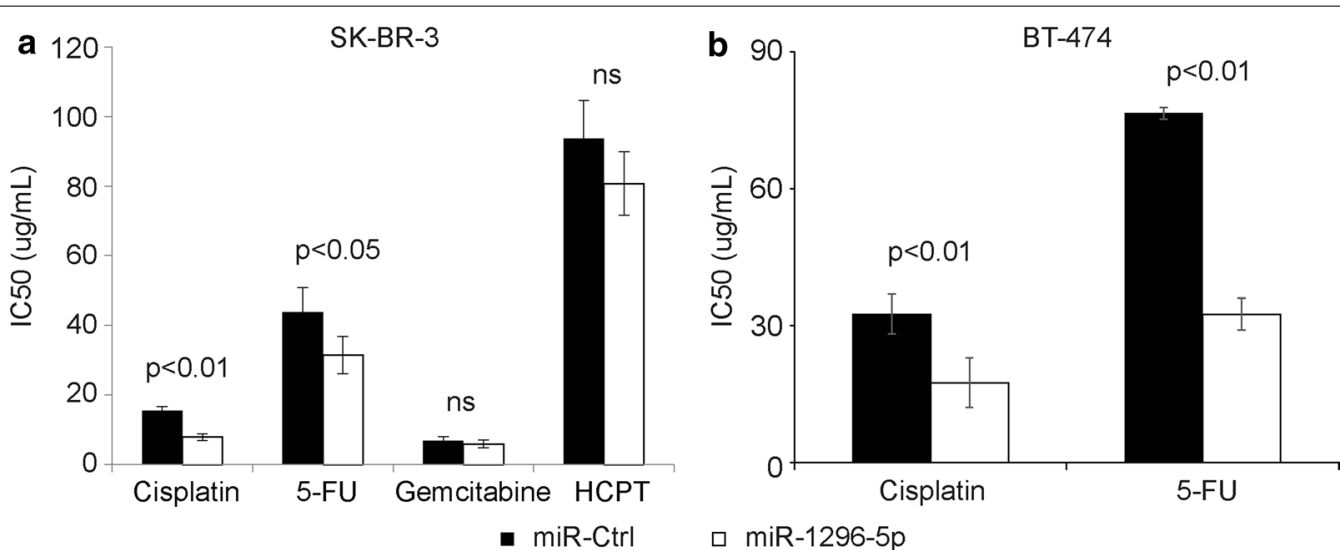

口 $\operatorname{miR}-1296-5 p$

Fig. 6 MiR-1296-5p sensitizes cells to chemotherapy drugs. a, b Overexpression of miR-1296 in SK-BR-3 or BT-474 breast cancer cells significantly sensitized cells to cisplatin and 5-fluorouracil (5-FU) treatment as compared to control miRNA. Cells were treated with cisplatin $24 \mathrm{~h}$ following miR1296-5p transfection and the cell viability was assessed after $48 \mathrm{~h}$ of cisplatin treatment. 5-FU, 5-fluorouracil. HCPT, hydroxy camptothecin. ns no significance

\section{Conclusions}

In summary, this study demonstrate that miR-1296-5p might be involved in the regulation of proliferation in human breast cancer cells via targeting ERBB2/mTORC1 signaling pathway. Therefore, miR-1296-5p is a tumor suppressor in breast cancer and a potential clinical diagnostic marker and therapeutic target for human breast cancer.

\section{Abbreviations}

TNBC: triple negative breast cancer; RTK: receptor tyrosine kinase; IHC: immunohistochemistry; mTOR: mammalian target of rapamycin; qRT-PCR: quantitative real-time PCR; 5-FU: 5-fluorouracil; HCPT: hydroxy camptothecin; NGS: next generation sequencing; LCL: lymphoblastoid cell line; CHF: congestive heart failure; MCM2: minichromosome maintenance 2; MTT: 3-(4,5-dimethylthiazol-2-yl)-2,5-diphenyl-tetrazolium bromide; IC50: 50\% inhibition of growth.

\section{Authors' contributions}

GC, $M H$ and $Y Y$ performed the experiments. $L Z$ and $H Z$ performed all the scoring of the IHC. WZ, YZ and PL designed the study. WC and ZH supervised the experiments. YZ and TY wrote the manuscript. All authors read and approved the final manuscript.

\section{Author details}

1 Department of Oncology, The Affiliated Jiangning Hospital of Nanjing Medical University, Nanjing 210029, People's Republic of China. ${ }^{2}$ Department of Oncology, First Affiliated Hospital of Nanjing Medical University, Nanjing 210029, People's Republic of China. ${ }^{3}$ Department of Anesthesiology First Affiliated Hospital of Nanjing Medical University, Nanjing 210029, People's Republic of China. ${ }^{4}$ Department of Gynecology and Obstetrics, First Affiliated Hospital of Nanjing Medical University, Nanjing 210029, China. ${ }^{5}$ Safety Assessment and Research Center for Drug, Pesticide and Veterinary Drug of Jiangsu Province, Nanjing Medical University, Nanjing 211166, People's Republic of China. ${ }^{6}$ Department of Gastroenterology, First Affiliated Hospital of Nanjing Medical University, Nanjing 210029, People's Republic of China. ${ }^{7}$ Department of Physiology, Nanjing Medical University, Nanjing 211166, People's Republic of China. ${ }^{8}$ State Key Laboratory of Reproductive Medicine, Nanjing Medical University, Nanjing 211166, People's Republic of China.

\section{Acknowledgements}

Not applicable.

\section{Competing interests}

The authors declare that they have no competing interests.

\section{Availability of data and materials}

The manuscript contain all potential findings based on raw data analysis. Raw data can be obtained from authors on request.

\section{Consent for publication}

Not applicable.

\section{Ethics approval and consent to participate}

Ethical approval for the study was granted by the Clinical Research Ethics Committee, Nanjing Medical University. Written informed consent was taken from each participant.

\section{Funding}

Grants from the National Natural Science Foundation of China (81370516 to Wenfang Cheng, 81472703 to Yichao Zhu, 81672400 to Wei Zhu), a sponsorship of Jiangsu Overseas Research \& Training Program for University Prominent Young \& Middle-aged Teachers and Presidents to Yichao Zhu, and a grant from Joint Research Project of Southeast University \& Nanjing Medical University (2242017K3DN41) to Fangfang Shi \& Yichao Zhu.

\section{Publisher's Note}

Springer Nature remains neutral with regard to jurisdictional claims in published maps and institutional affiliations.

Received: 9 May 2017 Accepted: 13 October 2017

Published online: 24 October 2017

\section{References}

1. Fabi A, Mottolese M, Segatto $O$. Therapeutic targeting of ERBB2 in breast cancer: understanding resistance in the laboratory and combating it in the clinic. J Mol Med (Berl). 2014;92(7):681-95.

2. Slamon DJ, Godolphin W, Jones LA, Holt JA, Wong SG, Keith DE, Levin WJ, Stuart SG, Udove J, Ullrich A, et al. Studies of the HER-2/ neu proto-oncogene in human breast and ovarian cancer. Science. 1989;244(4905):707-12.

3. Chen H, Sun JG, Cao XW, Ma XG, Xu JP, Luo FK, Chen ZT. Preliminary validation of ERBB2 expression regulated by miR-548d-3p and miR-559. Biochem Biophys Res Commun. 2009;385(4):596-600. 
4. Hanahan D, Weinberg RA. Hallmarks of cancer: the next generation. Cell. 2011:144(5):646-74.

5. Yu D, Hung MC. Overexpression of ErbB2 in cancer and ErbB2-targeting strategies. Oncogene. 2000;19(53):6115-21.

6. Urruticoechea A, Rizwanullah M, Im SA, Ruiz ACS, Lang I, Tomasello G, Douthwaite H, Badovinac Crnjevic T, Heeson S, Eng-Wong J, et al. Randomized phase III trial of trastuzumab plus capecitabine with or without pertuzumab in patients with human epidermal growth factor receptor 2-positive metastatic breast cancer who experienced disease progression during or after trastuzumab-based therapy. J Clin Oncol. 2017. doi:10.1200/JCO.2016.70.6267

7. Thavendiranathan P, Amir E. Left ventricular dysfunction with trastuzumab therapy: is primary prevention the best option? J Clin Oncol. 2017;35(8):820-5.

8. Perez EA, Barrios C, Eiermann W, Toi M, Im YH, Conte P, Martin M, Pienkowski T, Pivot X, Burris H 3rd, et al. Trastuzumab emtansine with or without pertuzumab versus trastuzumab plus taxane for human epidermal growth factor receptor 2-positive, advanced breast cancer: primary results from the phase III MARIANNE Study. J Clin Oncol. 2017;35(2):141-8.

9. Niu J, Xue A, Chi Y, Xue J, Wang W, Zhao Z, Fan M, Yang CH, Shao ZM, Pfeffer $L M$, et al. Induction of miRNA-181a by genotoxic treatments promotes chemotherapeutic resistance and metastasis in breast cancer. Oncogene. 2016;35(10):1302-13.

10. Xue J, Chi Y, Chen Y, Huang S, Ye X, Niu J, Wang W, Pfeffer LM, Shao ZM Wu ZH, et al. MiRNA-621 sensitizes breast cancer to chemotherapy by suppressing FBXO11 and enhancing p53 activity. Oncogene. 2016;35(4):448-58.

11. Yuan Y, Anbalagan D, Lee LH, Samy RP, Shanmugam MK, Kumar AP, Sethi G, Lobie PE, Lim LH. ANXA1 inhibits miRNA-196a in a negative feedback loop through NF-kB and C-Myc to reduce breast cancer proliferation. Oncotarget. 2016;7(19):27007.

12. Majid S, Dar AA, Saini S, Chen Y, Shahryari V, Liu J, Zaman MS, Hirata H, Yamamura S, Ueno K, et al. Regulation of minichromosome maintenance gene family by microRNA-1296 and genistein in prostate cancer. Cancer Res. 2010;70(7):2809-18.

13. Liu ZY, He WH, Gao JL, Luo JH, Huang X, Gao CF. Computational prediction and experimental validation of a novel synthesized pan-PIM inhibitor PI003 and its apoptosis-inducing mechanisms in cervical cancer. Oncotarget. 2015;6(10):8019-35.
14. Boo L, Ho WY, Ali NM, Yeap SK, Ky H, Chan KG, Yin WF, Satharasinghe DA, Liew WC, Tan SW, et al. MiRNA transcriptome profiling of spheroidenriched cells with cancer stem cell properties in human breast MCF-7 cell line. Int J Biol Sci. 2016;12(4):427-45.

15. Phan B, Majid S, Ursu S, de Semir D, Nosrati M, Bezrookove V, KashaniSabet M, Dar AA. Tumor suppressor role of microRNA-1296 in triplenegative breast cancer. Oncotarget. 2016;7(15):19519.

16. Liu J, Zhang Y, Xu R, Du J, Hu Z, Yang L, Chen Y, Zhu Y, Gu L. PI3K Akt-dependent phosphorylation of GSK3beta and activation of RhoA regulate Wnt5a-induced gastric cancer cell migration. Cell Signal. 2013:25(2):447-56.

17. Zhao DS, Chen Y, Jiang H, Lu JP, Zhang G, Geng J, Zhang Q, Shen JH, Zhou $X$, Zhu W, et al. Serum miR-210 and miR-30a expressions tend to revert to fetal levels in Chinese adult patients with chronic heart failure. Cardiovasc Pathol. 2013;22(6):444-50.

18. Johnson E, Seachrist DD, DeLeon-Rodriguez CM, Lozada KL, Miedler J, Abdul-Karim FW, Keri RA. HER2/ErbB2-induced breast cancer cell migration and invasion require p120 catenin activation of Rac1 and Cdc42. J Biol Chem. 2010;285(38):29491-501.

19. Tornillo G, Bisaro B, Camacho-Leal Mdel P, Galie M, Provero P, Di Stefano P, Turco E, Defilippi P, Cabodi S. p130Cas promotes invasiveness of threedimensional ErbB2-transformed mammary acinar structures by enhanced activation of mTOR/p70S6K and Rac1. Eur J Cell Biol. 2011;90(2-3):237-48.

20. Lee JE, Hong EJ, Nam HY, Kim JW, Han BG, Jeon JP. MicroRNA signatures associated with immortalization of EBV-transformed lymphoblastoid cell lines and their clinical traits. Cell Proliferat. 2011;44(1):59-66.

21. Cakmak HA, Coskunpinar E, Ikitimur B, Barman HA, Karadag B, Tiryakioglu NO, Kahraman K, Vural VA. The prognostic value of circulating microRNAs in heart failure: preliminary results from a genome-wide expression study. J Cardiovasc Med (Hagerstown). 2015;16(6):431-7.

22. Klos KS, Wyszomierski SL, Sun M, Tan M, Zhou X, Li P, Yang W, Yin G, Hittelman WN, Yu D. ErbB2 increases vascular endothelial growth factor protein synthesis via activation of mammalian target of rapamycin/p70S6 K leading to increased angiogenesis and spontaneous metastasis of human breast cancer cells. Cancer Res. 2006;66(4):2028-37.

\section{Submit your next manuscript to BioMed Central and we will help you at every step:}

- We accept pre-submission inquiries

- Our selector tool helps you to find the most relevant journal

- We provide round the clock customer support

- Convenient online submission

- Thorough peer review

- Inclusion in PubMed and all major indexing services

- Maximum visibility for your research

Submit your manuscript at www.biomedcentral.com/submit
BioMed Central 